\title{
SCIENTIFIC REPRTS \\ OPEN Author Correction: Changes in regional heatwave characteristics as a function of increasing global temperature
}

\author{
S. E. Perkins-Kirkpatrick $\mathbb{1}^{1,2}$ \& P. B. Gibson ${ }^{1,2}$
}

Correction to: Scientific Reports https://doi.org/10.1038/s41598-017-12520-2, published online 25 September 2017

This Article contains an error in the legend of Figure 4.

"Ensemble spread (99th percentile - 1st percentile) of increases in the number of heatwave projected by the CMIP5 ensemble (blue) and CESM ensemble (purple) per $0.5^{\circ} \mathrm{C}$ global warming, for (a) Alaska; (b) the Mediterranean; (c) Australia; (d) East Asia; (e) the Amazon, and (f) East Africa. These regions were chosen as they are representative of all 21 regions analysed. Note that the spread due to internal variability (estimated from CESM) is reasonably consistent across the thresholds. See table S.2 for region boundaries".

should read:

"Ensemble spread (99th percentile - 1st percentile) of increases in the number of heatwave days projected by the CMIP5 ensemble (blue) and CESM ensemble (purple) per $0.5^{\circ} \mathrm{C}$ global warming, for (a) Alaska; (b) the Mediterranean; (c) Australia; (d) East Asia; (e) the Amazon, and (f) East Africa. These regions were chosen as they are representative of all 21 regions analysed. Note that the spread due to internal variability (estimated from CESM) is reasonably consistent across the thresholds. See table S.2 for region boundaries".

Additionally, this Article contains an error in the title of Table 3.

"Median estimate of warming per ${ }^{\circ} \mathrm{C}$ global warming due to internal variability. (CESM(99th-1st)/CMIP5 (99th-1st))".

should read:

"The fraction (expressed as a percentage) of change in each regional heatwave characteristic due to internal variability. $100 *(\operatorname{CESM}(99$ th-1st $) /$ CMIP5 (99th-1st))".

(i) Open Access This article is licensed under a Creative Commons Attribution 4.0 International License, which permits use, sharing, adaptation, distribution and reproduction in any medium or format, as long as you give appropriate credit to the original author(s) and the source, provide a link to the Creative Commons license, and indicate if changes were made. The images or other third party material in this article are included in the article's Creative Commons license, unless indicated otherwise in a credit line to the material. If material is not included in the article's Creative Commons license and your intended use is not permitted by statutory regulation or exceeds the permitted use, you will need to obtain permission directly from the copyright holder. To view a copy of this license, visit http://creativecommons.org/licenses/by/4.0/.

(C) The Author(s) 2018

${ }^{1}$ Climate Change Research Centre, UNSW Australia, NSW, 2052, Australia. ${ }^{2}$ ARC Centre of Excellence for Climate System Science, UNSW Australia, NSW, 2052, Australia. Correspondence and requests for materials should be addressed to S.E.P.-K. (email: Sarah.kirkpatrick@unsw.edu.au) 